\title{
Boost Teaching Qualities: Processing Level and Bad Social Psychological Signals Detection
}

\author{
Peng Zhao ${ }^{1, a}$, Lan $\mathrm{Ma}^{2, \mathrm{~b}}$ \\ ${ }^{1}$ ChengDu College of University of Electronic Science and Technology of China, No.1, Baiye \\ Road, Chengdu, 611731, PR China \\ ${ }^{2}$ Sichuan TOP IT Vocational Institute, No.2000, Xiqu Avenue, Chengdu, 611743, PR China \\ aaccroc@163.com, b45736943@qq.com
}

Keywords: Level of processing, Overconfidence, Self-serving bias, Learned helplessness, Teaching reform

\begin{abstract}
From the perspectives of individual cognitive vs social psychological process in classroom teaching, an quantitative experimental analysis shows that by changing the processing level, the process based teaching modality has improved the students' average scores of the course intermediate financial accounting with better stability because of a smaller variance. By means of behavior observations and textual semantic analyses, the paper discusses qualitatively some social psychological phenomena, such as overconfidence, self-serving bias, learned helplessness, may be bad signals to predict students' poor academic performance. So, all the teaching related personnel can provide necessary help for the students in a dilemma to boost teaching qualities.
\end{abstract}

\section{Introduction}

After thriving for about ten years, independent colleges ${ }^{1}$ have to focus on education qualities rather than the number of enrollment under the pressure of market demands. Accounting is popular in these colleges but the teaching effects are far below satisfactions. Without fully grasping the basic accounting principles such as the double-entry bookkeeping, etc. and lacking practical job experiences, new understanding obstacles and journalizing difficulties occur during the teaching of the course intermediate financial accounting, which takes multifarious flexible accounting to different economic tractions or events as its purpose. So, how to improve the teaching qualities about this course become a thorny problem.

Though teaching based on cases, scenarios, projects, discussions, role-playing, and skills competitions, etc. had been tried to improve the classroom teaching effects, researches rooted both on individual unique cognitive process and psychosocial process seem not sufficient. In light of this, we choose cognitive psychology [1] and social psychology [2] as the two major theoretical pillars to discuss the curriculum intermediate financial accounting reform.

The paper focuses on: Dose cognitive circulation system, namely from knowledge construction, preliminary processing, and smooth processing to skillful use, improve the course grades effectively? Regarding a class as a small society, are there any kind of social psychological phenomena related to the students' poor academic performance? Understanding the two questions will help us to choose

${ }^{1}$ In China, universities or colleges are usually funded by government, while independent colleges are invested by nongovernmental capital. 
specific teaching methods from the perspective of improving students' cognitive abilities and to aid those who with adverse social psychological phenomena in time. We employ an experiment to quantitatively discuss the first question, and use observation or semantic analyses to explore the second question.

\section{Quantitative Analysis: Processing Level and Teaching Effects}

From the perspective of cognitive psychology, first of all, understanding is a constructive process [3], in which the learners can't understand the new knowledge unless it has been related smoothly to the old known. When students generally lack of some necessary knowledge related to the new knowledge, teachers should help them construct a cognitive foundation through cases, role experience, etc. Second, the constructive process at a low processing level needs more chances to strengthen toward smooth processing. In fact, the process can be divided into preliminary processing and smooth processing, the latter means the students realized their comprehension. In addition, smooth processing needs to be transformed into practical skills to meet the vocational requirements. All the above mentioned are intertwined, not complied with strict sequence. Now we define traditional vs process based teaching modalities.

Traditional teaching modality. Traditional classroom teaching is prevailing in independent colleges and usually criticized for its boring, dull and inefficient. Teachers lecture almost every chapter one by one, then assign exercises and put up the keys. Generally they do not pay special attention to the students' cognitive construction and processing level, or just a certain degree of attention, but rarely set detection means to involve themselves in students' cognitive obstacles.

Process based teaching modality. If the knowledge construction, preliminary processing, smooth processing and skilled use are treated as a cognitive circulation, we do the following to enhance students' processing level in our classroom:

Deconstruct the knowledge of each chapter by analyzing, numbering every knowledge pieces.

Compile daily life related cases to introduce important views on some economic events.

Guide the students to preliminary processing through the classroom exercises after illustrating the accounting principles by examples.

Probe the students understanding barriers by requiring the students to reiterate some knowledge pieces in their words or by imitation practices.

The curriculum lecturers provide further explanations and some specific exercises to those students in deep confusion after the collection and summarization of all the questions asked by students.

Provide more comprehensive training to help students fortify their processing level.

Quantitative research design. Limited by personal energies, the advancement of the teaching equipment and other factors, it is difficult for the teachers to involve themselves effectively into students' cognitive activities and get active feedbacks in large scale classes comparing to small scale classes. In order to control the effect of the class size, we chose 100 sophomores majoring in accounting specialty enrolled in 2014, who were divided into two classes, an experimental class and a reference class, randomly by the educational administration system. Each class had 50 subjects and the two classes were coached by the same teacher. The experimental class was taught by process based teaching modality and the reference traditional teaching modality. At the end of the semester in January 2016, we analyzed whether the process based teaching modality was helpful to improve the student's exam scores or not by comparing the experimental class to the reference class with statistical significance.

Quantitative results and discussion. We present variables definition, descriptive statistics and t-test results in the following tables. 
Table 1 Variables for test

\begin{tabular}{cc}
\hline Variable & Variable Meaning \\
\hline $\begin{array}{c}\text { scoreexper } \\
\text { scoreref }\end{array}$ & final test scores of the intermediate financial accounting course in experimental class \\
\hline
\end{tabular}

Table2 Summary statistics

\begin{tabular}{cccccc}
\hline Variable & Obs & Mean & Std. Dev. & Min & Max \\
\hline scoreexper & 50 & 74.02 & 7.296882 & 60 & 90 \\
scoreref & 50 & 67.62 & 8.794456 & 46 & 89 \\
\hline
\end{tabular}

Table3 Comparison of the effect of teaching modality on performance in different subjects

\begin{tabular}{ccccccc}
\hline Variable & Obs & Mean & Std. Err. & Std. Dev. & \multicolumn{2}{c}{$[95 \%$ Conf.Interval] } \\
\hline scoreexper & 50 & 74.02 & 1.031935 & 7.296882 & 71.94625 & 76.09375 \\
scoreref & 50 & 67.62 & 1.243724 & 8.794456 & 65.12064 & 70.11936 \\
diff & 50 & 6.4 & 1.592072 & 11.25765 & 3.200611 & 9.599389 \\
\hline
\end{tabular}

Mean (diff) $=$ mean (scoreexper - scoreref)

Ho: mean $($ diff $)=0$

Ha: mean (diff) $<0$

Ha: mean (diff) $!=0$ $\mathrm{t}=4.0199$

$\operatorname{Pr}(\mathrm{T}<\mathrm{t})=0.9999$

$\operatorname{Pr}(|\mathrm{T}|>|\mathrm{t}|)=0.0002$

degrees of freedom $=49$

Ha: mean (diff) $>0$

$\operatorname{Pr}(\mathrm{T}>\mathrm{t})=0.0001$

$\mathrm{d}=\mathrm{MD} /$ Pooled $\mathrm{SD}=(74.02-67.62) /((7.30+8.79) / 2)=0.80$

An independent t-test was performed to identify if there were significant differences between different teaching modalities for college students in regard to their course intermediate financial accounting scores in different learning subjects. Table 3 indicates that there was a significant difference between the two teaching modalities for the college students sampled in regard to their intermediate financial accounting scores, $\mathrm{t}(49)=4.0199, \mathrm{p}<0.05$. On average, students taking classes in the process based teaching modality performed better than students taking classes in the traditional learning modality. Since the mean difference (MD) was 6.4 and the pooled standard deviation was approximately $8.045, \mathrm{~d}=0.80$, according to Cohen [4], indicated the large effect size.

Supplementary: Information gathered by teaching management staff through focus groups in the two classes shows that experimental class gave more positive evaluation such as "love", "attention", etc. to their teacher, but the reference class voiced no comments.

\section{Qualitative Analyses: Bad Social Psychological Signals Detection}

The quantitative analysis in the table 3 shows that by changing the level of processing, the process based teaching modality has improved the students' average scores of the course intermediate financial accounting with better stability under a smaller variance in the experimental class. Teachers can only judge some processing obstacles fed back by the majority at most time, unless the students report their confusion actively. Some shy or easy grades-chasing students, who are difficult to get instant help from their teacher, feel gradual difficult and eventually lose their confidence in learning. If put the students in the background of a small scale society for observations, what kind of typical social psychological phenomena can the teachers likely detected to predict some students' failures? Based on the theory of social psychology, we explore the issue by observing typical classroom behavior and by semantically analyzing the content of online chat conducted in all the samples.

Overconfidence. For the course intermediate financial accounting, all the subjects not only need to overcome the understanding obstacles, but also to practice repeatedly so as to get professional 
proficiencies. Good understanding abilities don't mean high scores because of lack required degree of proficiencies. We list gradually subjects who have good understanding abilities through observation, questioning, etc. and marked them as two types, diligent vs idle in classroom practice for preliminary processing, without telling them. The former were usually on the top percentile of the final test scores and the latter's overconfidence made them feel good and brought them control illusion [5]. Because the latter didn't fulfil their cognitive cycles effectively regardless of reminding, we inferred that this part of subjects' final performance would be not well, so did the actual results.

Self-serving bias. We also observed that some students' enthusiasm decreased progressively as time went on. With the increased degree of difficulty, they seated themselves from the front to the back. In some conversations, they usually gave the excuses that they needed to participate in the activities of the students' union or any other pretexts, which is a typical phenomenon of self-serving bias, a poor signal for them who had many difficulties in learning.

Learned helplessness. Using instant messaging software such as Tencent QQ, we communicated privately with those subjects seemed to do very hard but to score very bad in learning. From the semantic analyses of the content in our online chats, even though we had explained that the course itself was difficult for beginners to get more than 45 scores, they still insisted that they were too dull to grasp it and lacked of confidence. More seriously, they inclined to reject explicit encouragement. We think that these students had suffered learned helplessness and low resilience [6] for long-term learning frustrations.

\section{Conclusions}

This study employs experimental method to analyze quantitatively whether process based teaching modality is better than the traditional or not. Then some qualitative discussions are applied to explore the links between some social psychological phenomena and academic failures. We draw the conclusions as, first, though each student has its unique cognitive process, focusing on individual understanding obstacles can improve the performance with statistical significance, second, good understanding ability can improve the processing level on the one hand, but at the same time may cause the illusionary control because of their overconfidence, thus reduce the learning effect, third, some bad social psychological phenomena can qualitatively predict students' failures, when these phenomena are observed, all the teaching related personnel shall consider whether they need to intervene the students' learning process in advance to provide effective help. Such as the classmates disturbed by learned helplessness, teachers may give them personalized guidance to make them pay more attention to the striving process and to relieve their anxiety stepwise.

\section{References}

[1] Robert J. Sternberg. Cognitive Psychology, third ed., Thomson/Wadsworth, Australia, 2003.

[2] Myers, David G. Social Psychology, eleventh ed., McGraw-Hill, New York, 2012.

[3] MS Poplin, Holistic/Constructivist Principles of the Teaching/Learning Process: Implications for the Field of Learning Disabilities, J. Learn. Disabil., 1988, 21(7):401-16.

[4] Cohen, J. (1988). Statistical power analysis for the behavioral sciences. Hillsdale, NJ: Lawrence Erlbaum Associates.

[5] Suzanne C. Thompson. Illusions of Control: How We Overestimate Our Personal Influence, Curr.

Dir. Psychol., Volume 8, Number 6, 1999.

[6] Emmy E. Werner. Resilience in Development, Curr. Dir. Psychol., Volume 4, Number 3, 1995. 